\title{
INFLUENCE OF THE CHANGING LOCAL CLIMATE ON WIND POTENTIALS OF MOUNT KOPAONIK
}

\author{
UDC 621.7
}

\author{
Predrag Živković ${ }^{1}$, Mladen Tomić ${ }^{2}$, Dragana Dimitrijević ${ }^{1}$, \\ Ivana Kecman $^{3}$, Mirko Dobrnjac ${ }^{2}$ \\ ${ }^{1}$ University of Niš, Faculty of Mechanical Engineering, Niš, Serbia \\ ${ }^{2}$ University of Novi Sad, Faculty of Technical Sciences, Novi Sad, Serbia \\ ${ }^{3}$ University of Banjaluka, Faculty of Mechanical Engineering Banjaluka, \\ Republic of Srpska, Bosnia and Herzegovina
}

\begin{abstract}
Obtaining all acceptable locations is one of the main tasks for siting wind turbines. The economic factors are usually very limiting. Very thorough analyses are needed in order to ensure the project finalization. Nevertheless, even after all the steps are made, some problems may occur. One of them is the real status of the winds in the so-called climatology period. This paper focuses on the influences of the changing winds after the preliminary estimations are done. The estimations are obtained using the WAsP simulation software. The results are compared in terms of quality and quantity of the wind data and capacity factor. Finally, an economic analysis is done.
\end{abstract}

Key Words: Wind Power Assessment, Complex Terrain, WAsP, Climatic Changes

\section{INTRODUCTION}

Energy, especially electrical, is of vital importance in the world today. Many assessments of fuel resources, mostly fossil, clearly indicate that these resources, especially oil ones, are almost exhausted. The need for energy constantly rises so that the introduction of new resources is inevitable. All these facts point to the necessity of transition to the sustainable development, especially to the usage of renewable energy sources. In that sense, wind energy clearly takes a prominent place considering its large potentials, purity and availability. The present constrains are mostly of financial nature. The most important task is the siting of wind turbines (obtaining the best possible locations for installing the turbines, considering

Received September 20, 2017 / Accepted November 28, 2017

Corresponding author: Predrag Živković

University of Niš, Faculty of Mechanical Engineering, Aleksandra Medvedeva 14, Niš, Serbia

E-mail: pzivkovic@masfak.ni.ac.rs 
the possibility for energy production and minimization of losses). For that purpose, the wind atlas method is developed as an easy one for usage in view of the rapid computer development. The position of a wind turbine is in strong correlation with energy production. According to the previous research [1-3], linear models cannot estimate correctly wind energy potentials in the terrain where the ruggedness index (index that represents the terrain slope value) exceeds 0.3 . In such a case, using full CFD models, followed by experimental validation is necessary. Even if all of the above mentioned is satisfied, there is still a possibility that the wind farm is not going to have the predicted output during the project lifetime, which is 25-30 years, which is about the same as the climatic period, which lasts for 32 years. A number of researchers have estimated Serbia's wind potentials [3-6]. Important research was done on atmospheric turbulence [7] and the methods of measuring wind potentials in the complex mountainous terrains of Serbia [8]. There are some papers considering the wind influence on other renewable energy sources [9], energy storage [10, $11]$ and advanced simulation models $[12,13]$.

\section{MATHEMATICAL MODEL}

CFD models are more precise but they need much more computational time. Considering the need to obtain the results as soon as possible, the best micro model was extracted from the larger macro model using the fast linear software [14]. Then the best wind turbine locations were obtained by using CFD software[15].

\subsection{Linear model}

A linear model is expressed by the following set of equations:

- Continuity equation

$$
\frac{\partial}{\partial x_{i}}\left(\rho U_{i}\right)=0
$$

- Logarithmic vertical wind profile

$$
U_{z}=\frac{U_{*}}{\kappa}\left(\ln \frac{z}{z_{0}}-\psi\right)
$$

- Weibull distribution equations

$$
\begin{gathered}
f(U)=\frac{K}{A}\left(\frac{U}{A}\right)^{K-1} \exp \left[-\left(\frac{U}{A}\right)^{K}\right] \\
F(U)=\exp \left[-\left(\frac{U}{A}\right)^{K}\right]
\end{gathered}
$$

where $x_{i}$ are the coordinates in index notation, $\rho$ air density, $U_{i}$ are the velocity components, $U_{z}$ is the vertical wind speed component at height $z$ above ground level, $U_{*}$ is the friction velocity, $\kappa$ is the von Kármán constant $(\kappa=0,4), z$ the height above ground level, $z_{0}$ is the surface roughness length, $\psi$ the empirical function, $K$ and $A$ are factors for the Weibull 
distribution, $f$ is the frequency of the wind speed occurrence and $F$ is the cumulative Weibull distribution.

Representative of the linear software packages is WAsP [14]. It calculates the speedup effects of the hills, taking into consideration the effect of energy redistribution in the flow from the component in the flow direction to the vertical component.

\subsection{Nonlinear model}

A nonlinear model solves the full set of governing equations of the steady fluid flow by using:

- Continuity equation:

$$
\frac{\partial}{\partial x_{i}}\left(\rho U_{i}\right)=0
$$

- Momentum equations:

$$
U_{j} \frac{\partial U_{i}}{\partial x_{j}}-\frac{\partial}{\partial x_{j}} v_{e f f}\left(\frac{\partial U_{i}}{\partial x_{j}}+\frac{\partial U_{j}}{\partial x_{i}}\right)=-\frac{1}{\rho} \frac{\partial P}{\partial x_{i}}
$$

- Turbulence model equations:

$$
\begin{gathered}
U_{j} \frac{\partial k}{\partial x_{j}}-\frac{\partial}{\partial x_{j}}\left[\left(v+\frac{v_{T}}{\sigma_{k}}\right) \frac{\partial k}{\partial x_{j}}\right]=P_{k}-\varepsilon \\
U_{j} \frac{\partial \varepsilon}{\partial x_{j}}-\frac{\partial}{\partial x_{j}}\left[\left(v+\frac{v_{T}}{\sigma_{\varepsilon}}\right) \frac{\partial \varepsilon}{\partial x_{j}}\right]=\frac{\varepsilon}{k}\left(C_{\varepsilon 1} P_{k}-C_{\varepsilon 2} \varepsilon\right)
\end{gathered}
$$

where:

$$
\begin{gathered}
P_{k}=v_{T}\left(\frac{\partial U_{i}}{\partial x_{j}}+\frac{\partial U_{j}}{\partial x_{i}}\right) \frac{\partial U_{i}}{\partial x_{j}} \\
v_{e f f}=v+v_{T} \\
v_{T}=C_{\mu} k^{2} / \varepsilon
\end{gathered}
$$

where $P$ is the body acceleration, $P_{k}$ production of turbulence, $v, v_{\text {eff }}$ and $v_{T}$ are the kinematic, effective and turbulent viscosity, respectively, $k$ is the turbulent kinetic energy, $\varepsilon$ turbulence kinetic energy dissipation.

The modified set of model coefficients reads: $C_{\mu}=0,0324, C_{\varepsilon 1}=1,44, C_{\varepsilon 2}=1,92, \sigma_{k}=1,0$, $\sigma_{\varepsilon}=1,85$.

The set of the nonlinear partial differential equations is solved by the WindSim [15] software package. 


\section{COMBINED METHODOLOGY}

CFD models are more precise but they need much more computational time. Considering the need to obtain the results as soon as possible, the best micro model was extracted from the larger macro model.

The differences in wind energy estimations while using these different approaches are considerable. Many investigations were done on this subject, dealing with different aspects of the software operation.

Test model of Mount Seličevica [3] was chosen due to its adequate orography as can be seen in Fig. 1. It is shown that the WAsP predictions are about $30 \%$ larger than WindSim [15] ones (estimated wind speed is in range 7,75-15,54m/s for WAsP, and 4,96$12,64 \mathrm{~m} / \mathrm{s}$ for WindSim, as shown in Fig. 1), due to neglecting of the second-order terms in the momentum equations, Eq. (6).
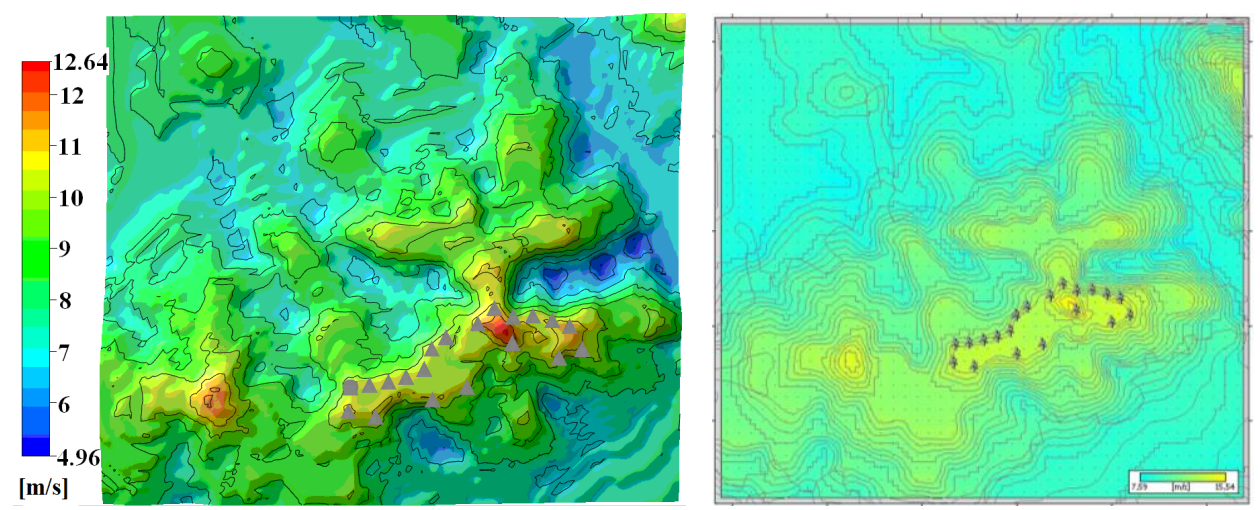

Fig. 1 Mean wind speed fields obtained by simulations in WAsP (left) and WindSim (right)

For obtaining the results the nesting technique is used. It assumes the boundary conditions in the initial simulation to be the terrain on the bottom, geostropic wind on the top and logarithmic wind profiles on the lateral sides of the domain at the macro level. Reducing the size of the domain in the following simulations, the lateral boundary conditions are results of the previous simulation, and not the theoretical profile, which significantly increases the quality of the results for the final micro location.

Simulations were done for the Enercon E82 wind turbine. It is very appropriate to use WAsP as the initial software at the mezzo level estimations, and WindSim for more precise micro level estimations, as the computational time for WAsP is about 20 times less than for WindSim.

In the previous papers $[4,5]$ results obtained by numerical simulation on over a dozen micro locations are presented. The considered locations mainly cover the mountainous regions of Southern and Eastern Serbia.

In this paper, the influence of the changing wind potentials from the main meteorological station Kruševac on the potentials of Mount Kopaonik was investigated. Size of the mezzo model was about $5000 \mathrm{~km}^{2}$.

Although there is a meteorogical station on Mount Kopaonik, Kruševac station (about $50 \mathrm{~km}$ away, Fig. 2) was chosen for having more data available for analysis. Another 
reason was that, as it is known that the harsh climate conditions on Kopaonik can cause the cup anemometer to freeze, the quality as well as the quantity of the data in the Kruševac station is better.

\section{KoPAONIK WIND POTENTIALS}

Mount Kopaonik (also known as Silver Mountain) region is situated in the central southern part of Serbia. It is the largest mountainous region in Serbia, stretching in a northwest-to-southwest direction for about $75 \mathrm{~km}$, with the widest part in the mid-section for about $40 \mathrm{~km}$. A large part is conserved as the Kopaonik national park. It is the largest skicenter in Serbia. The highest altitude is Pančić's Peak at $2017 \mathrm{~m}$ asl. There is a large highland area with many peaks, as Karaman $(1934 \mathrm{~m})$, Gobelja (1834m), etc. South of Pančić's Peak, there are many single rises, namely, Čardak (1590m), Šatorica $(1750 \mathrm{~m})$, Oštro koplje $(1789 \mathrm{~m})$.

With about 200 sunny days annually, Kopaonik is also called Sunny Mountain. Its southern, high and open position averts the clouds, keeping the cold air in the surrounding low areas, so that the winter temperatures are not too low, which is very important considering the possibility of wind turbine blade frosting. Average yearly temperature is $3,7^{\circ} \mathrm{C}$. Snow lasts from mid-November to May, about 160 days annually. Precipitation levels are over $1000 \mathrm{~mm}$ annually.

The Kopaonik ski center has about $62 \mathrm{~km}$ of tracks and 25 ropeways with overall capacity of 32000 skiers per hour.

Chosen wind turbine type is Enercon E-82, with unit power of 2MW. Considered micro model was chosen by former simulation on the bigger model, from which, using the nesting technique, the named model is obtained.

For the turbine siting the method of wake loss minimization and maximal annual energy production was used. Also, the recommendations about distance between wind turbines for the siting were as follows: in the wind direction minimally 7D (D - rotor diameter) and in the normal direction $4 \mathrm{D}$.
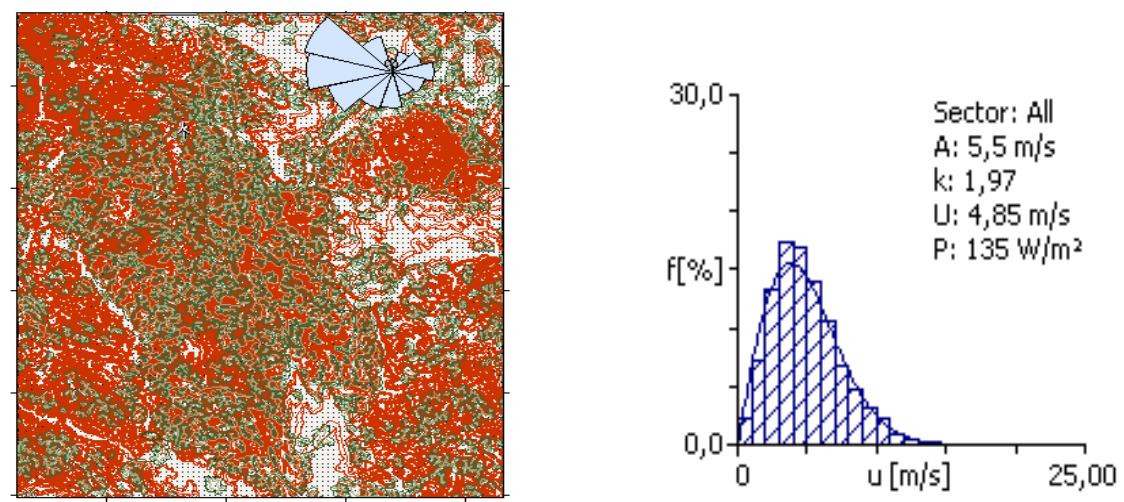

Fig. 2 Macro model with wind rose (left) and Weibull distribution (right) 
After the simulation is done, using the nesting technique, the micro model is obtained, and the field of annual energy production (AEP) is presented in the following figure (range being 4,483-13,087 [GWh]):
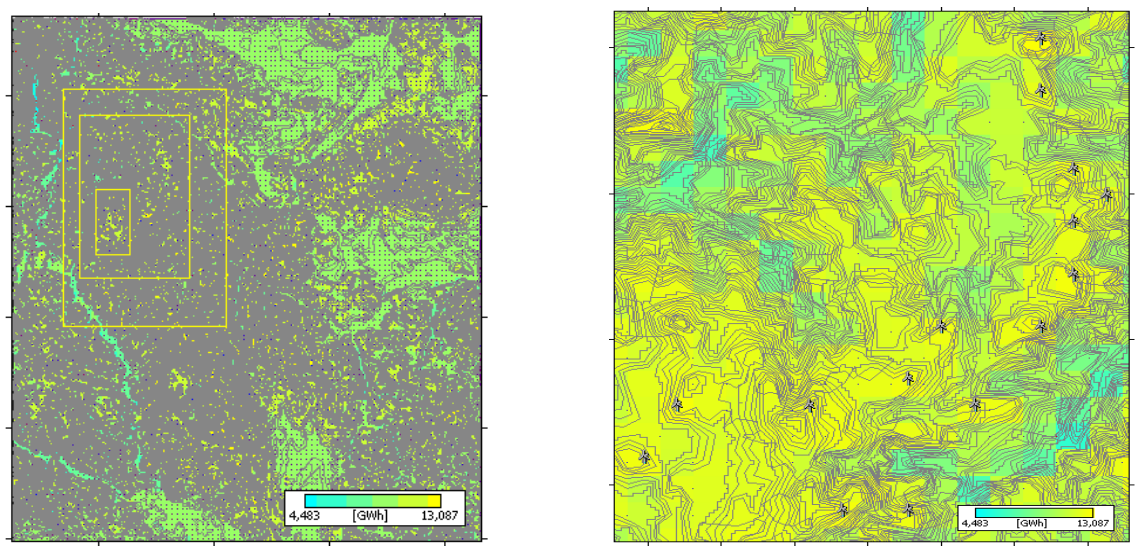

Fig. 3 Nesting technique (left) and AEP field with 15 turbine wind farm disposition (right)

From Fig. 2 one can notice that only the best locations are considered though there are possibilities for more locations to choose.

Table 1 AEP data for the 15 turbine Kopaonik wind farm

\begin{tabular}{lcccc}
\hline Parameter & Total & Average & Min & Max \\
\hline Gross AEP [GWh] & 188,79 & 12,59 & 12,26 & 12,99 \\
Net AEP [GWh] & 188,65 & 12,58 & 12,26 & 12,99 \\
Wake loss [\%] & 0,08 & - & - & - \\
\hline
\end{tabular}

Stable wind data (for 15 year period, minimum needed is 13 years) were obtained from the main meteorological station Kruševac. As the turbine acceptable wind speed is in the range of $2 \div 25 \mathrm{~m} / \mathrm{s}$, only $38,16 \%$ of the wind data are in the acceptable range. Considering this, as well as the overestimation by the used software, the capacity factor (ratio between possible AEP and max AEP) is calculated to be $C_{P}=0,21$. It is considered that the economically acceptable locations are with $C_{P}=0,25$ or higher.

On the basis of the data obtained by simulation, and the known turbine power, capacity factor $C_{p}$ can be calculated for the considered wind farm. The capacity factor is the ratio of the overall power output of a wind farm to its nominal output (if working on the full potential) for a period of time or for the case considered, annually. This can be presented in the form:

$$
C_{p}=\frac{A E P \cdot 0,3816}{8760 \cdot P t \cdot 1,3}
$$

where $P_{t}$ is installed power of the farm with 15 wind turbines Enercon E-82, 0,3816 is the percentage of accepted data (all the others can be considered as calm, i.e. $<2 \mathrm{~m} / \mathrm{s}$ ) and factor 1,3 is as the WAsP software overprediction, as shown earlier [3]. 


\section{Changing local Climate}

After the preliminary analysis was done [6], the wind data was obtained for the period 2014-2016. For this period the wind potentials were estimated for each annual data in order to compare the potentials of each year in the mentioned period.

Results are presented in the form of the wind roses and Weibull distributions for each year, as well as the AEP for the same farm, for each year.

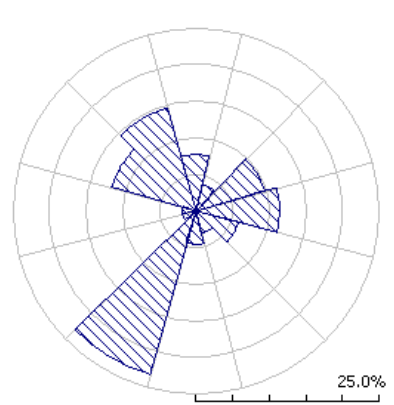

a)

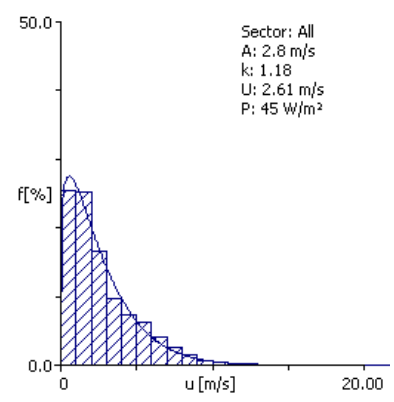

d)

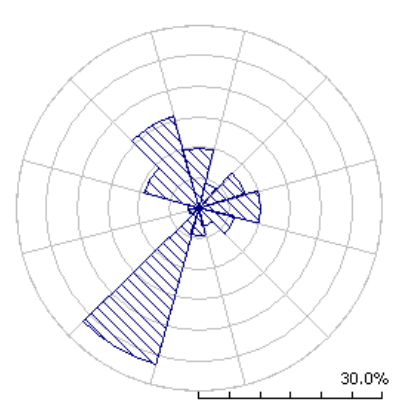

b)

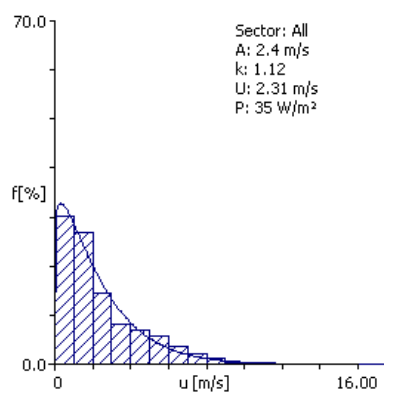

e)

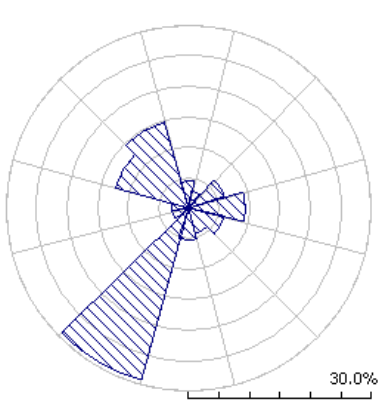

c)

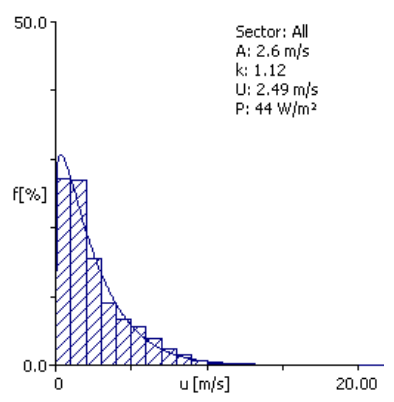

f)

Fig. 4 Wind roses (a, b, c) and Weibull distributions (d, e, f) for seasons 2014, 2015 and 2016, respectively

One can notice that there is a slight, but notable difference in the wind data. The slight decrease of the potentials can be noted as is presented in the Fig. 4.d-f. There is also a change of the wind speed distributions, shown on the wind roses, Fig. 4.a-c.

In Fig. 5, AEP fields for each year 2014, 2015 and 2016 are presented. One can notice that not only the potentials have slightly decreased, but even the best locations are slightly shifted to the east. As it is impossible to move the turbines after the installation, this shift is not going to be discussed in more detail. 


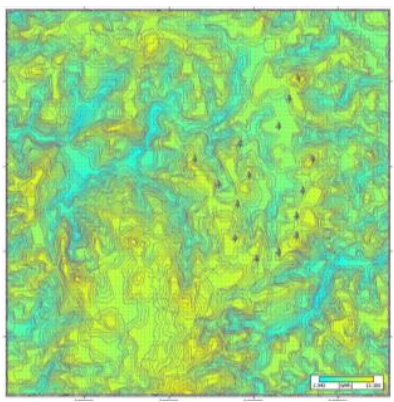

a)

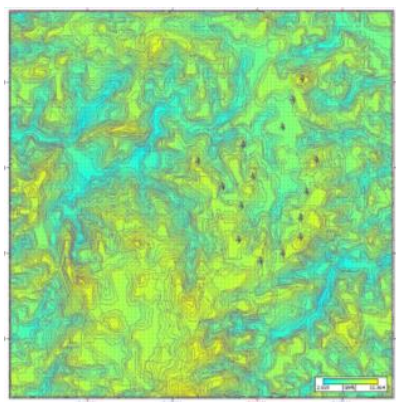

b)

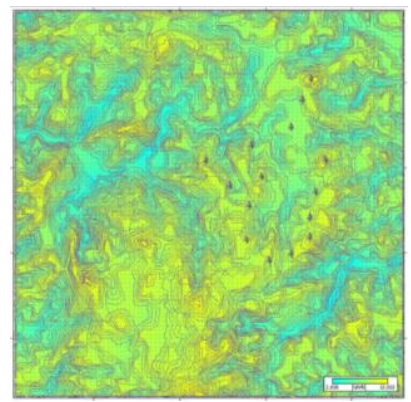

c)

Fig. 5 AEP fields for the year of: a) 2014, b) 2015 and c) 2016

It is already mentioned that capacity factor $C_{p}$ was 0,21 for long-term measured data. In the similar manner, the annual values for $C_{p}$ can be calculated for the considered period 2014-2016. The summary results are presented in Table 2.

Table 2 Capacity factor $C_{p}$ change for the period 2014-2016

\begin{tabular}{lcccc}
\hline Period & Long term & 2014 & 2015 & 2016 \\
\hline$C_{p}[-]$ & 0,2056 & 0,2197 & 0,1854 & 0,2041 \\
Accepted data [\%] & 38,16 & 50,70 & 44,06 & 47,44 \\
\hline
\end{tabular}

There are some fluctuations but the decreasing trend is obvious. The differences are mainly in the region of the lower wind speeds, which are increased, but the overall decrease is up to $10 \%$, compared to the long-term data.

In order to improve the predictions in the presented research, validation of the data should be done by on-site measurements $[9,10,11]$. As the potentials are near the acceptable margin of potentials $\left(C_{p} \sim 25 \%\right)$, there is a possibility for combining the system with solar or other types of RES $[12,13]$, in order to increase efficiency. Some new approaches to the problem of the wind farm production estimations can also be implemented [14].

\section{ECONOMIC ANALYSIS}

Economic analysis is one of the most important parts of every project. Renewable energy, including wind energy, is not an exception. Having in mind current prices of wind turbines, state of the global and local financial markets, and the fact that the local infrastructure is not very developed, a preliminary financial analysis was done. The initial assumptions are: the farm will operate for 25 years; initial investment is 49,5 million EUR; subventions will be 10\%; annual discount rate will be $10 \%$; annual inflation will be $7 \%$; increase of the electricity price will be $12 \%$ per annum. Expected electricity price is 94EUR/MW, for the period of the current feed-in tariff.

The basic financial indicators, well known from the literature, such as income rate in the first year, a simple and dynamic payback time, a net present value of the investment, an internal rentability rate, a benefit/cost ratio and lifelong cost savings were chosen for analysis. The estimated financial indicators are shown in Table 3. 
Table 3 Financial indicators

\begin{tabular}{llcccc}
\hline Financial indicators & & $2014-2016$. & 2014 & 2015 & 2016 \\
\hline Rate of income (year 01) & ROI [\%] & $-0,46$ & 0,18 & $-1,08$ & $-0,36$ \\
Simple payback time & SPB [year] & 16,75 & 15,18 & 18,63 & 16,49 \\
Net present value & NPV [EUR] & 53109782 & 61197811 & 45235053 & 54349251 \\
Benefit/cost ratio & B/C [-] & 14,09 & 14,68 & 13,44 & 14,18 \\
Lifelong cost savings & LCS [EUR/year] & 5851002 & 6742045 & 4983459 & 5987552 \\
\hline
\end{tabular}

Using the above listed financial indicators, it is calculated that the annual income of the Kopaonik wind farm could be about 2,71 million EUR annually over the chosen period 2014-2016. It shows that the project payback time is over 15 years, which makes this project hardly affordable. One can notice from Table 3 that the best production would be for 2014, the lowest for 2015, while slightly increased for 2016. It would be interesting to see its value at the end of the current year (2017).

\section{CONCLUSION}

Wind energy is one of the fastest growing renewable energy resources. Most of the EU members are using it widely. Yet, the available usable locations are not limitless. This gives an opportunity to the less developed countries to use available funds within the scope of $20 \%$ of energy in Europe to be produced by renewable sources.

Koponik region is relatively far from the power sources. Installing wind turbines could significantly improve the quality of the energy supply in this area, which is very desirable, having in mind the extensive ski-center, the largest in Serbia, and one of the largest in Europe, with tendency of expanding the capacities.

According to the data presented in Table 2, it is obvious that the potentials of this site, which are already barely profitable, are actually decreasing. A more thorough financial analysis is needed in order to confirm such findings. Such findings are very valuable, as the first wind turbines are currently being installed in the northern part of Serbia.

Nevertheless, the excess energy production compared to the consumption in this area is almost $80 \%$ for the summer and about $60 \%$ for the winter season [8]. Such excess energy can be sent to the distribution network, towards other consumers. As there is no other power source in the $100 \mathrm{~km}$ radius, any new source can drastically improve the power supply quality, especially having in mind the mentioned ski-center.

Closeness of the large energy consumer as the Kopaonik ski-center can reduce network losses, as the consumers are almost on-site. Also, the power supply quality is very important for the people living in the area.

Acknowledgements: This paper is part of the work within the National Program of Energy Efficiency, project number: TR33036, funded by the Government of Republic of Serbia. I extend my gratitude to my dear co-mentor Žarko Stevanović and the colleagues from the Vinča Institute, Laboratory for thermal engineering and energy, for the help with the simulations in both WAsP and WindSim, whose licences they possess. 


\section{REFERENCES}

1. Schaffner, B., 2003, Wind Modeling in Mountains: Intercomparison and Validation of Models, study for METEOTEST, Bern, Switzerland and ${ }^{2}$ VECTOR AS, Tonsberg, Norway.

2. Llombart, A., Talayero, A., Mallet, A, Telmo, E., 2006, Performance analysis of wind resource assessment programs in complex terrain, Renewable Energy and Power Quality Journal, 1(4), pp. 301-306.

3. Živković, P., Wind energy estimations in terrain with complex orography - comparative methodology analysis, 2006, Magister thesis, Faculty of Mechanical engineering, Niš, 72 p.

4. Schneider, D.R., Paprika M., Delalić N, Lekić A., Bajramović R., Teskerdžić A., Smajević I., Džaferović E, Begić F., Lulić H., Metović S., Petrović S.I., Đugum A., Kadrić Dž., Hodžić N., Kulić F., Kazagić A., Mladenović R., Erić A., Belošević S.V., Duić N., Raguzin I., Bogdan Ž., Ban M., Grubor B., Stefanović P., Dakić D.V., Repić B., Stevanović Ž., Žbogar A., Studović M., Nemoda S. Đ., Oka N., Đurović D., Kadić N., Bakić V.V., Gafić A., 2007, Mapping the potential for decentralized energy generation based on RES in Western Balkans, Thermal Science, 11(3), pp 7-26.

5. Živković, P., Ilić, G., Stevanović, Ž., 2008, Wind Power Assessment in Complex Terrains of Serbia, Proc. 21st International Conference on Efficiency, Cost, Optimization, Simulation and Environmental Impact of Energy Systems, Cracow-Gliwice, Poland, pp 1141-1148.

6. Živković, P. Tomić M., Petković D., Ćirić I., Stevanović Ž.Ž., Dimitrijević D, Dobrnjac S., Ćirić M., 2015, Possibilities of wind energy usage in the ski center Kopaonik, Proc. 12th Anniversary International Conference on Accomplishments in Electrical and Mechanical Engineering and Information Technology DEMI 2015, Banjaluka, Bosnia and Herzegovina, pp. 373-378.

7. Stevanović, Ž.M., Mirkov, N.S., Stevanović, Ž.Ž., Stojanović, A.D., 2010, Validation of atmospheric boundary layer turbulence model by on-site measurements, Thermal Science, 14(1), pp 199-207.

8. Pezo, M.L., Bakić, V.V., Marković, Z. J., 2016, Structural analysis of guyed mast exposed to wind action, Thermal Science, 20(S5), pp S1473-S1483.

9. Bakić, V. V., Živković, G. S., Pezo, M. L., 2011, Numerical simulation of the air flow around the arrays of solar collectors, Thermal Science, 15(2), pp 457-465.

10. Bakić, V.V., Pezo M.L, Jovanović M.P, Turanjanin V.M., Vučićević B.S., Mirkov N.S., 2012, Technical analysis of photovoltaic/wind systems with hydrogen storage, Thermal Science, 16(3), pp 865-875.

11. Bakić, V.V., Živković, G.S., Pezo, M.L., 2016, Techno-economic analysis of stand-alone photovoltaic/ wind/battery/hydrogen systems for very small-scale applications, Thermal Science, 20(S1), pp S261-S273

12. Živković, P., Nikolić V., Ilić G., Ćojbašić Ž., Ćirić I., 2012, Hybrid soft computing control strategies for improving the energy capture of a wind farm, Thermal Science, 16(S2), pp S483-S491.

13. Stevanović, Ž., 2008, Numerical aspects of turbulent momentum and heat transfer, (in Serbian), University of Niš, Faculty of mechanical engineering, p. 351

14. Website: www.wasp.dk (last access: 10.Nov. 2017).

15. Website: https://windsim.com (last access: 10.Nov. 2017). 